\title{
Factors Affecting Farmers' Adoption of Agricultural Innovations: A Panel Data Analysis of the Use of Artificial Insemination among Dairy Farmers in Ireland
}

\author{
Peter Howley \\ Environment Department, University of York, Y010 5DD, United Kingdom \\ E-mail: peter.howley@york.ac.uk \\ Cathal O. Donoghue \\ Rural Economy Development Programme, Teagasc, Athenry, Galway, Ireland \\ E-mail: peter.howley@teagasc.ie \\ Kevin Heanue \\ Rural Economy Development Programme, Teagasc, Athenry, Galway, Ireland \\ E-mail: peter.howley@teagasc.ie
}

Received: June 9, 2011 Accepted: June 23, 2011 Online Published: April 26, 2012

doi:10.5539/jas.v4n6p171

URL: http://dx.doi.org/10.5539/jas.v4n6p171

\begin{abstract}
The use of artificial insemination (AI) has been of enormous economic benefit for dairy farmers in many countries such as Ireland through the genetic improvement of their stock. Despite these benefits a significant proportion of dairy farmers continue to use natural mating over AI. Previous research has found that the cost of semen, the cost of insemination and success rate all affect the probability of farmers using AI. Using a nationally representative panel dataset, this paper examined if there were any farm or farmer characteristics that affected the probability of dairy farmers using AI. Modelling the farm factors driving the uptake of AI enables the understanding of the differences between various types of landowners which should in turn better equip policymakers to design policies and programs that efficiently promote good reproductive management. The results in this paper suggest that there is significant heterogeneity among farm households in relation to the uptake of AI with both characteristics of the farmer as well as structural farm factors all found to significantly affect the probability of a farmer adopting this agricultural innovation.
\end{abstract}

Keywords: Artificial insemination, Dairy farmers, Ireland, Agricultural innovations

\section{Introduction}

The use of artificial insemination (AI) as a method of reproduction, particularly in the dairy sector, has been of enormous economic benefit through the genetic improvement of milk production, the control of venereal and other diseases and the reduction of lethal genes (Vishwanath, 2003; Watson, 1990; Shannon, 1978). AI is now widely used in the dairy as opposed to the beef industry as dairy cows are observed every day thus making it easier to inseminate them when they come into oestrus. Although the immediate result from using AI is the impregnation of the dairy cow, the real benefit is that it gives all farmers the possibility of gaining from genetic improvements created elsewhere (Chupin and Thiber, 1995). In addition to AI, a range of reproductive technologies have been developed over the last number of decades. These include progesterone-based and prostaglandin based oestrous synchronisation regimens, ovsynch-regimens for ovulation, embryo transfer and more recently "sexed semen" (Moore and Thatcher, 2006; Mapletoft and Hasler, 2005; Pursley et al., 1997; Foote, 1996). Due to its relative simplicity and low cost AI still remains, however, the most common method of reproductive technology employed by dairy farmers in Ireland. While reproductive efficiency is important in all systems it is considered to have a higher importance in seasonal calving systems found commonly in countries such as Ireland, New Zealand and Australia (Dillon et al., 2006; Walsh et al., 2011). 
Previous research has found that the cost of semen, the cost of insemination and success rate all affect the probability of farmers using AI (Vishwanath, 2003). The aim of this paper is to examine if there are any characteristics of the farm household and structural farm factors that affect the probability of farmers adopting this innovation. It is important to understand factors influencing the adoption of reproductive technologies in that reproductive management of dairy cattle is crucial to whole-farm profitability. In this paper we utilise a 15 year panel dataset taken from the Irish National Farm Survey (NFS) which contains information on approximately 300 dairy farmers each year to examine if background personal characteristics of the farmer as well as structural farm factors affect the utilisation of AI. First by way of background this paper discusses previous research findings on factors affecting farmers' adoption of agricultural innovations. Next we describe the panel dataset used in the analysis. The results of the study are presented in section 4 and finally section 5 concludes with a discussion of the papers main findings and their relevance for the agricultural sector.

\section{Factors Affecting Farmers' Adoption of Agricultural Innovations}

There is a large literature on the adoption of agricultural technology (for good overviews see Rogers, 2003; Sunding and Zilberman, 2001; Feder and Umali, 1993). Viewed through a broad cross disciplinary lens, there is agreement that the adoption of agricultural technology depends on a range of personal, social, cultural and economic factors, as well as on the characteristics of the innovation itself (Pannell et al., 2006). A meta level analysis of this type of research undertaken by Prokopy et al (2008) shows that education levels, capital, income, farm size, access to information, positive environmental attitudes, environmental awareness and utlilisation of social networks are generally positively, associated with the adoption of best management practices.

Narrowing the disciplinary focus, the agricultural economics literature on technology adoption emphasises the role of fixed and variable costs and heterogeneity, whether in terms of structural farm factors such as size or land quality, or the characteristics of farmers in terms of human capital (Sunding and Zilberman, 2001). Focusing on factors outside the farm gate, Fulginiti and Perrin (1993) report a positive relationship between past output prices and current productivity, while Miller and Tolley (1989) show that market interventions such as price supports can speed up the adoption of new technologies.

The characteristics of the technology itself are also an important influence on farmers' technology adoption and usage decisions (Adesina and Zinnah, 1993). In particular, the relative complexity, risk and investment characteristics of technologies significantly affect their adoption and diffusion (Batz et al, 1999). Looking at the differences between capital-intensive and management-intensive technologies, El-Osta and Morehart (2002) found that age, size and specialization in dairy production increased the likelihood of adopting a capital-intensive technology, whereas education and size of operation positively impacted the decision to adopt a management-intensive technology. In this context, the risk preferences of farmers are also important in influencing the technology adoption decision, especially if capital-intensive technology costs are irreversible (Sunding and Zilberman, 2001).

Other parts of the social science literature emphasise the role of distance and geography in the adoption of agricultural technologies (Rogers, 2003; Diamond, 1999). In this case, any significant travel costs involved in the initial learning about a technology and subsequently establishing it might reduce the likelihood of that technology's adoption. More recently, some economists and other social scientists have focused more explicitly on farmers' motivations, values, objectives and behavioural influences in the context of technology adoption (e.g. Rehman et al., 2007). This literature focuses on explaining how social norms, beliefs about a technology's performance and importance and farmers' intentions to change practices impact on the adoption of technologies. Finally, many studies concur that interaction with extension services (Millar, 2010; Garforth et al., 2003; Butcher, 1998) and peer-group behaviour (Sauer and Zilberman, 2010) also positively impact farmers' technology adoption decisions.

It is clear from this brief review of the general technology adoption literature that many explanatory variables are considered important. Specifically in relation to breeding technologies, Khanal and Gillespie (2011) report that in the US dairy sector specialised, younger, more educated farmers are more likely to adopt advanced breeding technologies such as AI, sexed semen and embryo transplants. An analysis of the use of AI for Ugandan dairy farmers revealed that the age of the farmer, years of awareness of the AI technology, total farm milk production and sales, extension visits per year, and quality of AI services provided to the farmers were positively associated with adoption and use of AI technology. The factors negatively associated with adoption and use of AI technology included farm level cost of AI services, farming experience, herd size and breed of animals (Kaaya et al, 2005). 
The analysis that follows adheres to the strand of the literature identified above that focus on heterogeneity in structural farm and farmer characteristics as explanatory variables for technology adoption patterns. Variables such as risk, education and farmers' attitudes towards technology are excluded from the analysis due to limitations in the data set used.

\section{Materials and Methods}

\subsection{The Panel Data Set}

The data source employed for this research is the Irish national farm survey (NFS), 1995 to 2009, which was set up in 1972 and has been published on an annual basis since. The NFS is collected as part of the Farm Accountancy Data Network of the European Union (FADN 2005). It determines the financial situation on Irish farms by measuring the level of gross output, costs, income, investment and indebtedness across the spectrum of farming systems and sizes and provides data on Irish farm income to the European Commission in Brussels and a database for economic and rural development research and policy analysis (Connolly et al. 2007). A random sample of approximately 1,100 farms are surveyed each year representing approximately 104,800 farms nationally and the farm system variable is broken down into six different categories: Dairying farmers only, Dairying and Other, Cattle rearing (specialist cattle-mainly rearing), Cattle Other (mixed livestock and/or specialist cattle-mainly fattening), Mainly Sheep and Tillage Systems. For the purpose of this analysis we focus specifically on dairy farmers as these are the farm types with the greatest proportion of AI utilisation.

The NFS represents data of the form $\mathrm{x}_{\mathrm{it}}$, where $\mathrm{x}_{i t}$ is a vector of observations for farmer $i$ in year $t$. The data analysed in this study uses 15 years of the NFS, 1995 to 2009 to model the utilisation of AI by dairy farmers in Ireland. The dataset is unbalanced in the sense that many farmers do not stay in the sample for the full 15 years. Some drop out permanently while others drop out in one year but re-enter in the following year. New farmers are introduced as well during the period to keep the whole sample representative and at the approximate 1100 figure. On average farm respondents participated in the sample over the reference period for 9.36 years. Once a farm remains in the sample for a 2 year period (which need not be concurrent) it may be used in the panel data model.

The Logit model is a standard method for understanding the association between explanatory variables and a binary dependent variable (Greene, 2003). The Probit model is another potential model, with a slightly different distributional structure, but producing qualitatively similar conclusions. We employ two variants of the model. Exploiting the panel nature of the National Farm Survey, we estimate a panel data random effects model. However as the dependent variable and many of the explanatory variables are relatively time invariant, we also estimate a pooled logit model.

A logit model can be specified in the form

$$
P(A I=1)=f\left(B_{1 i t} X_{1 i t}+B_{2 i t} X_{2 i t}+\ldots+B_{n i t} X_{n i t}+e_{i t}\right)
$$

where $\mathrm{f}(\mathrm{z})=\exp (\mathrm{z}) /(1+\exp (\mathrm{z}))$

As we observe individuals participation over time, it is possible using panel data methods to identify individual unobserved heterogeneity ui within the model in the following way

$$
P(A I=1)=f\left(B_{1 i t} X_{1 i t}+B_{2 i t} X_{2 i t}+\ldots+B_{n i t} X_{n i t}+u_{i}+e_{i t}\right)
$$

Here the individual heterogeneity effect is what is known as a random effect as the model is estimated on a sample of the population. The model estimated the impact of characteristics of the farmer such as age, off-farm employment, presence of children; structural farm factors such as gross margin per livestock unit and stocking rate; participation in agri-environmental schemes and farm advisory services on the probability of a farmer using $\mathrm{AI}$ in any given year (see table 1 for a description of the structure of the variables utilised). These explanatory variables were chosen based on a review of the literature and a priori expectations of the characteristics that we believed should influence use of AI.

\section{Results and Discussion}

Table 2 examines the proportion of farmers who use AI as a reproductive technology across all livestock farm systems between 1996 and 2009. It can be seen that AI use varies quite significantly across the different farm systems. First it can be seen that AI is used by a relatively low proportion of sheep farm systems (.36). This would be expected given the relatively high proportional cost of using AI for sheep reproduction. In relation to the cattle farm systems (specialist dairy, dairy and other and the two cattle systems farms) it can be seen in table 2 that there are significant differences in the proportion of these farmers using AI. In particular, the proportion of farmers using $\mathrm{AI}$ in the farm systems predominantly concerned with rearing cattle for beef production (cattle rearing and cattle other) is substantially below the proportion of farmers who use AI in the two dairying systems. 
This would be consistent with trends in other countries where the majority of beef cattle are bred by natural service. AI is more widely used in the dairy industry as dairy herd cows are seen every day thus making it easier to inseminate them when they come into oestrus (Vishwanath, 2003). In contrast, cattle are much less sighted in a beef herd thus making it much more difficult for a farmer to detect when it is the appropriate time for insemination. For the purpose of this paper we focus specifically on examining if there are any characteristics of the farmer or structural farm factors that predict the uptake of AI by those in the specialist dairy farm system, who as can be seen table 2 have the highest proportional use of AI.

Table 3 outlines the proportion of farmers who use AI in any given year who also used $\mathrm{AI}$ in the previous period. Between 95 and 98 percent of farmers who used $\mathrm{AI}$ in any given year continue with its use in the following year. Therefore it can be seen that experience with $\mathrm{AI}$ is positively associated with the probability of a farmer using AI in a given year. It could be that once farmers have any experience with AI then the process becomes much easier in subsequent years thus making them more likely to continue with its use. Additionally it could be hypothesised that the positive relationship between previous experience with AI and its utilisation in any given year could be due to the fact that use of AI had a positive effect on the farm business thus making farmers more likely to continue with its application.

$<$ Table 1-3>

\subsection{Logit Model Analysis}

Table 4 presents the results of a pooled logit and random effects model to examine if personal characteristics or structural farm factors affect the probability of a farmer using AI in a given year. The model results indicate that there is a variety of farm and farmer related characteristics that affect the probability of dairy farmers using AI in a given year which are discussed below.

In comparing the random effects and pooled logit models, we note that while there is little qualitative difference between models, a number of coefficients in the random effects model are insignificant. The reason for this is that the individual effect and the explanatory variables are correlated, as evidenced by the failure of the Hausman test which tests for this assumption. So effectively, some of the information contained in the relatively time invariant variables is being included in the random effects model. As our dependent variable does not change that much over time, with relatively few transitions in and out of AI, what is of more interest is the type of farm that is more likely to be a long term user of AI. Our pooled logit model is sufficient for making this interpretation and in what follows below we focus on the results from the pooled logit model.

The reader should, however, be cautious in inferring causality between some of the explanatory variables with the dependent variable as there is likely to be significant endogeneity in models of this kind. So for example, while we observe that Teagasc clients are ceteris paribus more likely to use AI than non AI Teagasc clients, we cannot infer that it is Teagasc membership that drives them to use AI. It could be that the motivation to be a more profitable farmer drives both the decision to seek out extension support and at the same time use AI technologies. Assessing the causal impact of extension services on AI would require a proper experimental design, which is not really feasible in this situation. Nevertheless even if we cannot infer causality, associative results that are statistically significant help us to classify farmers that are more likely to use technologies helping in the design of better extension methodologies that can improve uptake.

\subsubsection{Personal Characteristics}

First age was negatively associated with AI use, in that relatively older farmers were found to be much less likely to use AI than younger age cohorts. It could be hypothesised that younger farmers may be better educated and therefore more aware of the benefits of reproductive technologies and also older farmers may be more conservative, less flexible and more sceptical about the benefits of AI utilisation. One further background variable found to affect the probability of farmers using AI was the presence of an off farm job. The use of AI can be much more labour intensive than using a bull to breed cows given the time required to observe cattle to detect when cattle are in heat and the time required assisting AI technicians. It could be hypothesised, therefore, that the negative relationship between having an off farm job and the use of AI could be attributable to labour costs and on farm labour availability. Farmers with children were also much more likely to use AI in a given period. It is difficult to ascertain without further qualitative work why farmers with children are significantly more likely to use AI on their farm. Perhaps these farmers are more likely to have a successor to continue on the farming business and are thus more concerned with having a profitable farm business to pass on to their heir. 


\subsubsection{Structural Farm Factors}

Farmers with relatively higher gross margins per livestock unit were more likely to use AI than farmers with relatively lower gross margins. It could be that relatively more profitable farms recognise the benefits of using $\mathrm{AI}$ as a reproductive technology and are therefore more likely to use this as opposed to natural mating. It must be noted, however, that it is possible that this variable at least to some degree is capturing the fact that farmers who use AI are themselves more likely to have a higher gross margin. Farmers with relatively higher stocking rates were also more likely to use AI although this variable was not statistically significant. Farm size was negatively associated with use of AI. It could be that once we control for gross margin and stocking rate that this variable is capturing the effect of being in a more extensive rather than intensive farm enterprise.

A further characteristic of the farm found to have an effect on farmers' utilisation of AI was participation in an agri-environmental scheme (REPS). Specifically farmers who participate in REPS are much less likely to use AI as a reproductive technology than non REPS farmers. Under this scheme farmers were given financial incentives to adopt less intensive farming practices in order to meet environmental objectives. It could be hypothesised that farmers participating in REPS may be diversifying away from profit maximisation and traditional forms of commercial agriculture and so may be less likely to use AI in the same way as other farmers. The effect of participating in a farm advisory programme (Teagasc) was found to have a positive effect on the probability of farmers using AI. It could be that advisory services help make farmers more aware of the potential benefits of using AI as a reproductive technique. In particular, farm advisory services could provide useful advice on the impact of using AI over other reproductive technologies and the most efficient method of using AI. It must be noted, however, that there is a potential endogeneity problem with the inclusion of this variable in that those who involve themselves with advisory services may be more likely to adopt best management practices irrespective of any advice or help they receive. Finally we included a cost index taken from the Central Statistics Office representing the cost of veterinary services in Ireland over time as farmers who wish to use AI generally need assistance from vets or AI technicians. This variable was statistically significant and negative indicating that the higher the costs of these services then the less likely it is that a farmer uses AI. In addition to the coefficients of the model, as it is difficult to directly interpret the coefficients in a logit model, we also report the marginal effects. We calculate the impact of a marginal change in each explanatory variable, with all variables valued at the mean value for that variable. We interpret the marginal effects as the impact of a $100 \%$ change in the explanatory variable. Thus moving into work was associated with a reduced probability of taking up AI by $10 \%$. Similarly joining Teagasc extension services is associated with an increase of $3 \%$ in the probability of using AI.

$<$ Table 4>

\section{Conclusion}

Good reproductive management of dairy cattle is crucial to whole-farm profitability. The use of artificial insemination in particular has been of enormous economic benefit for dairy farmers in many countries such as Ireland through the genetic improvement of their stock. Despite these benefits, a significant proportion (18\%) of specialist dairy farmers in Ireland continue to use natural mating over AI. Given the relatively high returns to the use of this technology due to improved breed quality, it is important to determine what factors affect farmers' decision to adopt AI. Previous research has determined that economic factors such as the cost of semen, cost of insemination as well as likelihood of success will affect the probability of farmers using reproductive technologies. This paper examined if there were any characteristics of the farmer as well as structural farm factors that affect the probability of farmers using AI.

A model of dairy farmers' utilisation of AI reproductive techniques allows a judgement to be made on the structural farm factors affecting the use of this agricultural innovation. More specifically, modelling the farm factors driving the uptake of AI enables the understanding of the differences between various types of landowners. This in turn it is hoped will better equip policymakers to design policies and programs that efficiently promote good reproductive management.

An important component of effective farm management is the willingness and ability of farmers to adopt appropriate new technologies (Altham and Guerin, 1999). AI has been identified as the single most important technique ever devised for the genetic improvement of dairy cattle. Many technologies such as AI that would benefit pasture-based milk production are not always, however, adopted by dairy farmers (Flett et al., 2004). The explanation for not using a particular farm technology is not always simply that it is irrelevant to farming needs (Austin et al., 1998). The reported heterogeneity in adoption behaviour reported in this analysis would suggest that factors such as the cost of using this technology, potential benefits and also ease of use which is largely dependent on the characteristics of the farmer will all significantly affect farmers adoption of AI. More 
specifically, the analysis found a negative relationship between the cost of veterinary services and the adoption of AI which suggests that cost is a significant factor affecting farmers' decision making in relation to the use of this agricultural innovation. Farmers who are, all things being equal, more likely to receive benefits from the use of AI such as those with higher gross margins per livestock unit are more likely to use AI.

One further factor that potentially affects the use of AI is labour supply with farmers having an off-farm job much less likely to adopt AI. This could be due to time constraints of the individual farmer in that the use of AI can be much more labour intensive than using a bull to breed cows. This means that irrespective of any potential economic benefits some farmers may simply not have the time to implement this technology. Older farmers were also less likely to adopt AI. Education has previously been found to have a positive association with the adoption of new technologies (Prokopy et al. 2008) and it could be that age as used in this analysis is capturing the fact that relatively older farmers are on the whole less educated than their younger counterparts. Additionally, it could be that older farmers are more conservative in relation to the uptake of new management practices. The presence of children was also positively associated with the uptake of AI and this could reflect a greater willingness on the part of farm operators to adopt best management practices when a potential farm successor is in place. Finally consistent with previous research which has found that involvement in farm advisory programmes is positively associated with farmers' adoption of best management techniques (Millar, 2010), farmers who participate in a farm advisory programme in Ireland were more likely to adopt AI.

Inadequacies within the NFS dataset include a lack of information on farmers' education and farmers' attitudes toward adoption of technologies (reproductive or otherwise). The inclusion of these in the model specifications, along with perceptions of the level of risk held by farmers towards the use of AI would add significantly to the knowledge about a farmers decision to utilise AI or not. Despite this shortfall the results in this paper still gives us rich farm specific information for a large number of farmers over a relatively long time horizon and the model allows us to make a judgement on the characteristics of farm households affecting farmers' decision making process.

\section{Acknowledgements}

The authors would like to thank the farm surveys department at Teagasc for providing the dataset used in this paper. The authors would also like to acknowledge the helpful comments provided by the editor and anonymous reviewers which helped us improve the analysis in this paper.

\section{References}

Adesina, A., \& Zinnah, M. M. (1993). Technology characteristics, farmers' perceptions and adoption decisions: A Tobit model application in Sierra Leone, Agricultural Economics, 9, 297-311. http://dx.doi.org/10.1016/0169-5150(93)90019-9

Altham, W. J. \& Guerin, T. F. (1999). Environmental self-regulation and sustainable economic growth: the seamless web framework. Eco-management and Audit, 6, 61-75. http://dx.doi.org/10.1002/(SICI)1099-0925(199906)6:2<61::AID-EMA103>3.0.CO;2-W

Batz, F. J., Peters, K. J., \& Janssen, W. (1999). The influence of technology characteristics on the rate and speed of adoption, Agricultural Economics, 21, 121 -130. http://dx.doi.org/10.1016/S0169-5150(99)00026-2

Butcher, S. (1998). Where do farmers get their information? Primary Industry Management, 1, 2, 12-15.

Chupin, D. \& Thiber, M. (1995). Survey of the present status of the use of artificial insemination in developed countries. World Anim Rev, 82, 58-68.

Connolly, L., Kinsella, A, Quinlan, G., \& Moran B. (2007). Irish National Farm Survey 2006. Teagasc Publication, Athenry, Galway.

Diamond, J. (1999). Guns, Germs and Steel. W.W. Norton and Company, New York.

Dillon, P., Berry, D, D. P., Evans, R. D., Buckley, F., \& Horan, B. (2006). Consequences of genetic selection for increased milk production in European seasonal pasture based systems of milk production. Livestock Science, 99 , 141-158. http://dx.doi.org/10.1016/j.livprodsci.2005.06.011

El-Osta, H. S., \& Morehart, M. J. (2002). Technology Adoption and Its Impact on Production Performance of Dairy Operations, Review of Agricultural Economics, 22, 2, 477-498. http://dx.doi.org/10.1111/1058-7195.00034

Farm Accountancy Data Network. (2005). Concept of FADN [online]. Available from: http://europa.eu.int/comm/agriculture/rica [Accessed 15 April 2008]. 
Feder, G., \& Umali, D. L. (1993). The Adoption of Agricultural Innovations: A Review, Technological Forecasting and Social Change, 43, 215-239. http://dx.doi.org/10.1016/0040-1625(93)90053-A

Flett, R., Alpass, F., Humphries, S., Massey, C., Morriss, S., \& Long, N. (2004). The technology acceptance model and use of technology in New Zealand dairy farming. Agricultural Systems, 80, 199-211. http://dx.doi.org/10.1016/j.agsy.2003.08.002

Foote, R. H. (1996). Review: Dairy cattle reproductive physiology research and management-past progress and future prospects. Journal of Dairy Science, 79, 980-990. http://dx.doi.org/10.3168/jds.S0022-0302(96)76449-4

Fulginiti, L. E., \& Perrin, R. K. (1993). Prices and productivity in agriculture, The Review of Economics and Statistics, 471-482. http://dx.doi.org/10.2307/2109461

Garforth, C., Angell, B., Archer, J., \& Green, K., (2003). Fragmentation or creative diversity? Options in the provision of land management advisory services, Land Use Policy, 20, 323-333. http://dx.doi.org/10.1016/S0264-8377(03)00035-8

Greene, W. (2003). Econometric Analysis: Fifth Edition. Prentice Hall, New Jersey.

Kaaya, H., Bashaasha, B., \& Mutetikka, D. (2005). Determinants of utilisation of artificial insemination (AI) services among Ugandan dairy farmers, African Crop Science Conference Proceedings, Vol. 7. pp. 561-567

Khanal, A. R., \& Gillespie, J. M. (2011). Adoption and Profitability of Breeding Technologies on United States Dairy Farms, Southern Agricultural Economics Association Annual Meeting, Corpus Christi, TX, February 5-8, 2011

Mapletoft, R. J., \& Hasler, J. F. (2005). Assisted reproductive technologies in cattle: a review. Rev. sci. tech, 24(1), 393-403.

Millar, J. (2010). The Role of Extension for Improving Natural Resource Management: the Australian Experience in Jennings J., Packham R., Woodside D. (Eds.) Shaping Change: Natural Resource Management, Agriculture and the Role of Extension. Australasia-Pacific Extension Network (APEN), Australia, 102-110.

Miller, T., \& Tolley, G. (1989). Technology Adoption and Agricultural Price Policy. American Journal of Agricultural Economics, November, pp. 847-857. http://dx.doi.org/10.2307/1242662

Pannell, D. J., Marshall, G. R., Barr, N., Curtis, A., Vanclay, F., \& Wilkinson, R. (2006). Understanding and promoting adoption of conservation practices by rural landholders. Australian Journal of Experimental Agriculture, 46, 1407-1424. http://dx.doi.org/10.1071/EA05037

Prokopy, L. S., Floress, K., Klotthor-Weinkauf, \& Baumgart-Getz. (2008). Determinants of agricultural best management practice adoption: Evidence from the literature. Journal of Soil and Water Conservation, 63, 5, 300-311. http://dx.doi.org/10.2489/jswc.63.5.300

Moore, K., \& Thatcher, W. W. (2006). Major advances associated with reproduction in dairy cattle. Journal of Dairy Science, 89, 1254-1256. http://dx.doi.org/10.3168/jds.S0022-0302(06)72194-4

Pursley, J. R., Kosorok, M. R., \& Wiltbank, M. C. (1997). Reproductive management of lactating dairy cows using synchronisation of ovulation. Journal of Dairy Science, 80, 301-306. http://dx.doi.org/10.3168/jds.S0022-0302(97)75938-1

Rehman, T., McKemey, K., Yates, C. M., Cooke, R. J., Garforth, C. J., Tranter, R. B., Park, J. R., \& Dorward, P. T. (2007). Identifying and understanding factors influencing the uptake of new technologies on dairy farms in SW England using the theory of reasoned action, Agricultural Systems, 94, 281-293. http://dx.doi.org/10.1016/j.agsy.2006.09.006

Rogers, E. M. (2003). Diffusion of Innovations. 5th ed. New York: The Free Press.

Sauer, J., \& Zilberman, D. (2010). Innovation Behaviour at Farm Level - Selection and Identification, 114th EAAE Seminar 'Structural Change in Agriculture', Berlin, Germany, April $15^{\text {th }}-16^{\text {th }}, 2010$.

Shannon, P. (1978). Factors affecting semen preservation and conception rates in cattle. $J$ reprod fertility, 54, 519-527. http://dx.doi.org/10.1530/jrf.0.0540519

Sunding, D., \& Zilberman, D. (2001). The Agricultural Innovation Process: Research and Technology Adoption in a Changing Agricultural Sector, in Gardner B and Rausser G (eds) Handbook of Agricultural Economics, Vol. 1, Elsevier Science B.V.

Vishwanath, R. (2003). Artificial insemination: the state of the art. Theriogenology, 59, 571-584. http://dx.doi.org/10.1016/S0093-691X(02)01241-4 
Walsh, S. W., Williams, E. J. \& Evans, A. C. O. (2011). A review of the causes of poor fertility in high milk producing dairy cows.

Watson, P. F. (1990). Artificial insemination and the preservation of semen. In: Lamming GE, editor. Marshall's physiology of reproduction. Edinburgh: Churchill livingstone, p. 747-789.

Table 1. Definition of variables used in the logit model

\begin{tabular}{|l|l|r|r|r|}
\hline \multicolumn{1}{|c|}{ Variable } & \multicolumn{1}{|c|}{ Definition } & \multicolumn{1}{c|}{ Nean } & \multicolumn{1}{c|}{ Std Dev } \\
\hline $\begin{array}{l}\text { Artificial } \\
\text { Insemination }\end{array}$ & Percentage of dairy farmers who use AI & 4555 & 0.82 & 0.38 \\
\hline Age & Age in years & 4548 & 48.43 & 13.96 \\
\hline $\begin{array}{l}\text { Veterinary } \\
\text { expenses }\end{array}$ & $\begin{array}{l}\text { Price index of veterinary expenses (source: } \\
\text { CSO) }\end{array}$ & 4555 & 101.58 & 27.82 \\
\hline Children & Proportion of dairy farmers who have children & 4555 & 0.55 & 0.50 \\
\hline Off-farm job & Proportion of farmers with an off-farm Job & 4555 & 0.10 & 0.31 \\
\hline $\begin{array}{l}\text { Gross margin } \\
\text { per livestock } \\
\text { unit }\end{array}$ & $\begin{array}{l}\text { Gross margin/(Number of dairy livestock units } \\
\text { + Number of cattle livestock units) }\end{array}$ & 4555 & 1321.12 & 398.24 \\
\hline Farmsize & Farmsize in hectares & 4555 & 49.03 & 27.30 \\
\hline Stocking rate & $\begin{array}{l}\text { (Number of dairy livestock units + Number of } \\
\text { cattle livestock units)/Farm Size }\end{array}$ & 4555 & 1.83 & 0.51 \\
\hline & $\begin{array}{l}\text { Proportion of dairy farmers who participate in } \\
\text { Teagasc advisory services }\end{array}$ & 4555 & 0.63 & 0.48 \\
\hline Teagasc & $\begin{array}{l}\text { Proportion of dairy farmers who participate in } \\
\text { the Rural Environment Protection scheme }\end{array}$ & 4555 & 0.21 & 0.41 \\
\hline Reps & & & \\
\hline
\end{tabular}

Table 2. AI Usage by Systems by Year (\%)

\begin{tabular}{|l|l|r|r|r|r|}
\hline Year & \multicolumn{2}{|l|}{$\begin{array}{l}\text { Specialist } \\
\text { Dairy }\end{array}$} & \multicolumn{1}{l|l}{$\begin{array}{l}\text { Dairy and } \\
\text { Other (Mixed) }\end{array}$} & \multicolumn{1}{l|}{$\begin{array}{l}\text { lattle } \\
\text { Rearing }\end{array}$} & \multicolumn{1}{l|}{$\begin{array}{l}\text { Cattle } \\
\text { Other }\end{array}$} \\
\hline 1996 & 0.87 & 0.86 & 0.56 & 0.55 & 0.48 \\
\hline 1997 & 0.89 & 0.86 & 0.60 & 0.49 & 0.45 \\
\hline 1998 & 0.88 & 0.86 & 0.58 & 0.51 & 0.44 \\
\hline 1999 & 0.87 & 0.88 & 0.59 & 0.52 & 0.42 \\
\hline 2000 & 0.91 & 0.81 & 0.63 & 0.53 & 0.46 \\
\hline 2001 & 0.88 & 0.87 & 0.59 & 0.47 & 0.42 \\
\hline 2002 & 0.87 & 0.77 & 0.64 & 0.42 & 0.42 \\
\hline 2003 & 0.85 & 0.73 & 0.58 & 0.36 & 0.46 \\
\hline 2004 & 0.85 & 0.80 & 0.55 & 0.35 & 0.45 \\
\hline 2005 & 0.85 & 0.81 & 0.52 & 0.30 & 0.33 \\
\hline 2006 & 0.83 & 0.70 & 0.49 & 0.30 & 0.28 \\
\hline 2007 & 0.82 & 0.61 & 0.50 & 0.29 & 0.25 \\
\hline 2008 & 0.82 & 0.50 & 0.48 & 0.29 & 0.27 \\
\hline 2009 & 0.82 & 0.64 & 0.53 & 0.24 & 0.29 \\
\hline Total & 0.82 & 0.73 & 0.54 & 0.37 & 0.36 \\
\hline
\end{tabular}


Table 3. Proportion of farmers using AI in a given period that used it in the previous period

\begin{tabular}{|l|r|}
\hline Year & 1 \\
\hline 1996 & 0.95 \\
\hline 1997 & 0.97 \\
\hline 1998 & 0.99 \\
\hline 1999 & 0.96 \\
\hline 2000 & 0.98 \\
\hline 2001 & 0.95 \\
\hline 2002 & 0.95 \\
\hline 2003 & 0.98 \\
\hline 2004 & 0.95 \\
\hline 2005 & 0.97 \\
\hline 2006 & 0.94 \\
\hline 2007 & 0.95 \\
\hline 2008 & 0.96 \\
\hline 2009 & 0.95 \\
\hline Total & 0.96 \\
\hline
\end{tabular}

Table 4. Logit models examining factors affecting dairy farmers' adoption of AI

\begin{tabular}{|l|c|c|c|}
\hline & Pooled model & $\begin{array}{c}\text { Marginal } \\
\text { effects } \\
\text { (pooled) }\end{array}$ & $\begin{array}{c}\text { Random } \\
\text { effects } \\
\text { model }\end{array}$ \\
\hline Age $* *$ & $-0.0213(.0038)^{* *}$ & -.0028 & $-.0308^{* *}$ \\
\hline Veterinary expenses $* *$ & $-0.0330(.0027)^{* *}$ & -.0043 & $-.0571^{* *}$ \\
\hline Children (no children is references category) ${ }^{* *}$ & $0.2794(.0882)^{* *}$ & .0372 & .2203 \\
\hline Off-farm job (no off farm job is reference category) $)^{* *}$ & $-0.6879(.1259)^{* *}$ & -.1084 & $-.6705^{* *}$ \\
\hline Gross margin per livestock unit ** & $0.0007(.0002)^{* *}$ & .0001 & $.0012^{* *}$ \\
\hline Farmsize ** & $-0.0048(.0015)^{* *}$ & -.0006 & -.0033 \\
\hline Stocking rate & $0.0900(.0850)$ & .0119 & .1497 \\
\hline Teagasc $*$ & $0.2169(.0898)^{*}$ & .02917 & $.0501^{*}$ \\
\hline Participation in REPS ** & $-0.3824(.1103)^{* *}$ & -.0543 & -.4355 \\
\hline Year dummies** & & & \\
\hline Log Likelihood & -1878 & & \\
\hline
\end{tabular}

** significance at $1 \%, * *$ significance at $5 \%$, Std. Error of pooled model coefficients in brackets 